\title{
Gestational diabetes mellitus-universal versus selective screening
}

\author{
Kaliki Hymavathi*, Surekha Tadisetti, Kavya Polisetty, Malini Devi Gottipatti
}

Department of Obstetrics and Gynaecology, NMCH, Nellore, Andhra Pradesh, India

Received: 29 March 2016

Accepted: 17 May 2016

*Correspondence:

Dr. Kaliki Hymavathi,

E-mail: drhymakrreddy@yahoo.co.in

Copyright: ( ) the author(s), publisher and licensee Medip Academy. This is an open-access article distributed under the terms of the Creative Commons Attribution Non-Commercial License, which permits unrestricted non-commercial use, distribution, and reproduction in any medium, provided the original work is properly cited.

\section{ABSTRACT}

Background: The prevalence of diabetes mellitus is increasing globally and Indian population is found to be ethnically in high risk group. Gestational diabetes mellitus (GDM) offers a unique and valuable opportunity for the development and implementation of clinical strategies for future prevention of diabetes. There is immense need for optimal screening strategies to spot out women with gestational diabetes.

Methods: Prospective case study.1000 pregnant women were recruited into the study at an early gestational age $(<20$ weeks). They were broadly divided into two groups A (without risk factors) and B (with risk factors). The whole study population (both A and B) is subjected to oral glucose challenge test (OGCT) with the concept of Universal screening. Those with abnormal OGCT are subjected to Oral glucose tolerance test (OGTT).Women with abnormal GTT values are designated as having GDM. The results are analyzed.

Results: $11.7 \%$ in group A and $25.4 \%$ in group B were found to have abnormal OGCT values and when they were subjected to OGTT $44.2 \%$ in group A and $45.8 \%$ in group B are detected to have abnormal OGTT values. $87.9 \%$ of GDM women were found to be in the age group 21-25 years in group A and in group B (59.5\%) were of $>26$ years. labor outcome by caesarean section in GDM cases was up to $60 \%$ and $51.3 \%$ being elective sections. On the whole neonatal outcome was satisfactory.

Conclusions: As Indian population are ethnically more prone for diabetes, there is immense need to adopt universal screening for GDM in pregnancy. Thus, a timely action can be taken as depicted in the present study by screening all pregnant women, irrespective of the presence/absence of risk factors.

Keywords: Gestational diabetes, Universal screening, Pregnancy outcome

\section{INTRODUCTION}

Diabetes mellitus is a metabolic disorder characterised by hyperglycaemia resulting from defects in Insulin secretion, action or both. Several distinct types of diabetes mellitus exist and are caused by a complex interaction of genetic, environmental factors and life style choices. ${ }^{1}$ The prevalence of diabetes mellitus in India, is found to be $2.4 \%$ in rural and $4-11.6 \%$ in urban population. High frequencies of impaired glucose tolerance ranging from 3.6-9.1\% indicate the potential for further rise in prevalence of diabetes mellitus in the coming decades. ${ }^{2}$ Normal pregnancy is associated with altered maternal glucose homeostasis and metabolism. It is important to identify a pregnant woman with GDM because of its association with significant metabolic alterations, increased perinatal and maternal morbidity and mortality leading to long term morbidity among the mothers and their off spring. ${ }^{3}$ The frequency of GDM and the associated morbidity emphasises the importance of an appropriate screening method. The screening of all pregnant women for GDM universally recommended in the second and third international workshops on GDM and the WHO expert committee on diabetes but the Fourth international workshop conference on GDM including American college of obstetricians and gynaecologists (ACOG) emphasised on selective screening. ${ }^{4-6}$ Is it possible to use selective screening based 
on risk factor identification that would identify the overwhelming majority of cases, be easy to implement, be cost effective, and would not lead to any harm? However it has been observed by the selective screening based on traditional risk factors, diagnosis of $35 \%$ of GDM cases will be missed. ${ }^{7}$ This study intends to project the importance of universal screening over selective screening for GDM detection in pregnant females.

\section{METHODS}

The sources of data was a prospective study conducted among pregnant women attending the obstetric department of Narayana medical college and hospital, Nellore, Andhra Pradesh, India a tertiary care center as outpatient (OP) or inpatient (IP).

Sample size in the study was 1000 pregnant women.

\section{Inclusion criteria}

Pregnant women with period of gestation $<20$ weeks.

\section{Exclusion criteria}

Diabetes mellitus prior to pregnancy. Pregnant women with period of gestation $>20$ weeks.

Patient analysis in institutional ethical committee of Narayana medical college and hospital, Nellore, Andhra Pradesh, India approved the study with the following ethical considerations.

- There should be no bias in sample selection with respect to age parity and socioeconomic status.

- An informed written consent is a must before recruiting in to the study.

- There should be no risk to women for being recruited in to the study.

- Confidentiality is mandatory

\section{Procedure of the study}

1000 pregnant women attending the obstetrics department of Narayana medical college and hospital Nellore, Andhra Pradesh, India were recruited in to the study as per the inclusion and exclusion criteria. History taking (demography, complaints, period of gestation, past history of medical, surgical and obstetrical), clinical examination (complete general, systemic and obstetric) routine antenatal investigations and special investigations like glucose challenge test, glucose tolerance test were done irrespective of presence or absence of risk factors. Any of the following were taken as risk factor and were noted.

- $\quad$ Age $>25$ years

- Obesity
- Previous bad obstetric history (history of abortion, unexplained IUD neonatal death, congenital anomalies).

- Previous history of macrosomia

- Previous history of GDM

- Family history of diabetes in first degree relatives

The study population is divided in to two groups. Group A without risk factors and group B with any of the above mentioned risk factors. Both groups are subjected to Universal screening by oral glucose challenge test (OGCT) Women with positive GCT are subjected to OGTT.

\section{Method of performing OGCT}

- Patient should be given 50 grams of glucose dissolved in $200 \mathrm{ml}$ of water taken over five to ten minutes irrespective of time and last meal.

- After 1 hour, $2 \mathrm{ml}$ of blood is drawn from the antecubital vein collected in to the vacutainer containing anticoagulant solution sodium fluoride and potassium oxalate in 1:3 ratios.

- The concentration of blood glucose is assessed by glucose oxidase method in autoanalyser.

- If blood glucose level is $\geq 140 \mathrm{mg} / \mathrm{dl}$, the test is considered positive and these women were subjected to OGTT.

- Women with blood glucose $<140 \mathrm{mg} / \mathrm{dl}$, test is considered as negative and OGCT repeated in $2^{\text {nd }}$ and $3^{\text {rd }}$ trimesters.

\section{Method of performing oral glucose tolerance test (OGTT)}

- $\quad$ Patient is advised to have three days of unrestricted carbohydrate diet and activity. Advised not to smoke on the day of testing.

- Fasting for a minimum of 8-12 hours prior to the test is advised. The test should start preferably by 8.30 $\mathrm{AM}$ as glucose tolerance worsens later in the day. Patient should sit throughout the duration of the test.

- Initial fasting blood sample is drawn following which the women is advised to drink 75 gm glucose dissolved in $300 \mathrm{ml}$ of water in five to ten minutes.

- Blood samples are collected at 1 hour and 2hours intervals following the ingestion of glucose and

\section{Glucose levels are estimated by glucose oxidase method.}

The diagnosis of GDM is made when any one of the following plasma glucose values are exceeded 85 :

- $\quad$ Fasting blood glucose level $\geq 92 \mathrm{mg} / \mathrm{dl}$

- 1 hour blood glucose level $\geq 180 \mathrm{mg} / \mathrm{dl}$

- $\quad 2$ hours blood glucose level $\geq 153 \mathrm{mg} / \mathrm{dl}$.

Women with normal OGTT values in the first trimester are advised for OGTT in second and third trimesters also 
so as not to miss, GDM cases setting in later stages of pregnancy.

\section{Statistical analysis}

Data was collected and tabulated as shown in results. Statistical analysis was done using Microsoft Excel. Frequency and percentage of each parameter was calculated and analyzed.

\section{Statistical software}

The data obtained was analyzed using SPSS software version 17.0 to generate graphs, tables etc.

\section{RESULTS}

Total study population (1000 pregnant women) were divided in to two groups: Group A (653) with no risk factors and group B (347) with one or more risk factors. All the women recruited were screened with OGCT(50 gm). Women with positive OGCT were subjected to OGTT-(75 gm) and if it is abnormal they were pronounced as having gestational diabetes mellitus (GDM).

Table 1: GCT (group A) - normal versus abnormal.

\begin{tabular}{|lll|}
\hline GCT group A & $(\mathrm{n} / \mathrm{t})$ & $\%$ \\
\hline Normal & 576 & $88.2 \%$ \\
\hline Abnormal & 77 & $11.7 \%$ \\
\hline
\end{tabular}

$\mathrm{t}=653$

Table 2: GCT (group B) - normal versus abnormal.

\begin{tabular}{|lll|}
\hline GCT group B & $(\mathrm{n} / \mathrm{t})$ & $\%$ \\
\hline Normal & 259 & $74.6 \%$ \\
\hline Abnormal & 88 & $25.4 \%$ \\
\hline $\mathrm{t}=347$ & & \\
\hline
\end{tabular}

Table 3: OGTT (group A) - normal versus abnormal.

\begin{tabular}{|lll|}
\hline Abnormal OGTT cases & $(\mathrm{n} / \mathrm{t})$ & $\%$ \\
\hline Normal & 46 & $59.7 \%$ \\
\hline Abnormal & 31 & $40.2 \%$ \\
\hline
\end{tabular}

Table 4: OGTT (group B) - normal versus abnormal.

\begin{tabular}{|lll|}
\hline Abnormal GTT cases & $(\mathrm{n} / \mathrm{t})$ & $\%$ \\
\hline Normal & 45 & $51.1 \%$ \\
\hline Abnormal & 43 & $48.9 \%$ \\
\hline $\mathrm{t}=88$ & & \\
\hline
\end{tabular}

In group A, majority were in the age group of 21-25 years (89.7\%). Among these women, 77 cases (11.7\%) were found to have abnormal OGCT values (Table 1), when they were subjected to OGTT, 31 cases (44.2\%) are detected to have abnormal values and were diagnosed as
GDM (Table 3). In group B 59.5\% of women were of 2635 years. 88 cases $(25.4 \%)$ among these were having abnormal OGCT (Table 2) and when subjected to OGTT, $43(48.9 \%)$ cases were found to have abnormal OGTT and were diagnosed as GDM (Table 4). Combining group $\mathrm{A}$ and $\mathrm{B}, 74$ cases were diagnosed as GDM thus making the prevalence of GDM as $7.4 \%$ (3.1 and $4.3 \%$ in groups $A$ and $B$ respectively (Table 5). In the whole lot of GDM cases diagnosed majority were multigravidas.

Table 5: Study population - abnormal OGTT.

\begin{tabular}{|lll|}
\hline Abnormal OGTT Cases & $(\mathrm{n} / \mathrm{t})$ & $\%$ \\
\hline Group A & 31 & $41.8 \%$ \\
\hline Group B & 43 & $58.1 \%$ \\
\hline $\mathrm{t}=74$ & & \\
\hline
\end{tabular}

Risk factors in the diagnosed GDM cases were found to be in descending order viz: age $>25$ years $(88.35 \%)$, obesity $58.1 \%$, family history of DM and H/o IUD $34.8 \%$ (Table 6).

Table 6: Diagnosed GDM (group B) - risk factors.

\begin{tabular}{|lll|}
\hline Risk factors & $(\mathbf{n} / \mathbf{t})$ & $\%$ \\
\hline Age $>$ 25 years & 38 & 88.3 \\
\hline Obesity & 25 & 58.1 \\
\hline H/o IUD & 4 & 9.3 \\
\hline H/o Macrosomia & 5 & 11.6 \\
\hline H/o neonatal loss & 9 & 20.9 \\
\hline H/o Congenital anomalies & 3 & 6.9 \\
\hline H/o Abortion & 11 & 25.5 \\
\hline H/o GDM & 11 & 25.5 \\
\hline Family H/o Diabetes & 15 & 34.8 \\
\hline t $=43$ & & \\
\hline
\end{tabular}

The various pregnancy complications observed were Hydramnios (12.1\%), preterm labour and PIH (5.4\%) each (Table 7).

Table 7: GDM versus maternal complications.

\begin{tabular}{|lll|}
\hline Complications & $\mathrm{n} / \mathrm{t}$ & $\%$ \\
\hline Hydramnios & $9 / 74$ & 12.1 \\
\hline Preterm labour & $4 / 74$ & 5.4 \\
\hline PIH & $4 / 74$ & 5.4 \\
\hline Infections & $2 / 74$ & 2.7 \\
\hline
\end{tabular}

Table 8: Mode of delivery.

\begin{tabular}{|lll|}
\hline Mode of delivery & $\mathrm{n} / \mathrm{t}$ & $\%$ \\
\hline Spontaneous VD & 10 & 13.5 \\
\hline Instrumental VD & 19 & 25.6 \\
\hline Elective LSCS & 38 & 51.35 \\
\hline Emergency LSCS & 7 & 9.4 \\
\hline
\end{tabular}

$\mathrm{t}=74$ 
With regard to labour outcome caesarean section rate was $60 \%$ and $51.3 \%$ being elective sections. $25.6 \%$ Vaginal deliveries were instrumental, mostly by ventuose, the predominant indication being uterine inertia (Table 8).

Table 9: GDM versus neonatal outcome.

\begin{tabular}{|lll|}
\hline Neonatal Outcome & $(\mathrm{n} / \mathrm{t})$ & $\%$ \\
\hline Normal & 57 & 77 \\
\hline Fresh still born & 1 & 1.35 \\
\hline IUGR & 5 & 6.7 \\
\hline Preterm & 4 & 5.7 \\
\hline Congenital anomalies & 1 & 1.35 \\
\hline Hypoglycemia & 2 & 2.7 \\
\hline Macrosomia & 4 & 5.4 \\
\hline $\mathrm{t}=74$ & & \\
\hline
\end{tabular}

Neonatal outcome was satisfactory in $77 \%$ of cases. There was one unexplained stillbirth $(1.3 \%)$ and one anomalous baby with VSD $(1.3 \%)$ which was diagnosed only after delivery. Fetal macrosomia ( $>4 \mathrm{~kg}$ ) was observed in $5.4 \%$ of cases. Out of four cases of macrosomia three cases belong to group B and one from group A (Table 9).

\section{DISCUSSION}

Gestational diabetes mellitus (GDM) is one of the most common medical disorders found in pregnancy. Clinical recognition of GDM is important because failure to identify a woman with GDM denies her the opportunity to have treatment for potentially preventable serious fetal complications contributing to perinatal morbidity and mortality. It is perhaps, for this effect of intrauterine programming that the disorder is most worthy of detection. A short term intensive care not only results in safe motherhood but also gives a long term pay off in the primary prevention of obesity and diabetes in the offspring as the "preventive medicine starts before birth". The prevalence of GDM ultimately reflects the background rate of type 2 diabetes. Over the years, there have been many controversies regarding GDM including best screening test, diagnostic test and indeed, whether treatment does modify pregnancy outcome. Some of the questions were answered, while in some areas, consensus is still to be reached. There is no universal agreement on the screening strategies and diagnostic criteria of GDM till date. This study is done with an ultimate goal to achieve how best we can detect women with GDM and how best to avoid the associated adverse maternal and fetal outcomes.

The incidence of diabetes in the world at large and in India particularly is on the rise. Getahun and colleagues showed that the prevalence of GDM in the United states more than doubled over a period, increasing from $1.9 \%$ to $4.2 \%$ (from $1989-99$ to $2003-2004$ ). Indian population is ethnically more prone to high prevalence of type 2 diabetes mellitus and in such population incidence of GDM is also expected to be high. In a study done by Dahiya $\mathrm{K}$ and et al, out of 500 pregnant females studied,
$35(7 \%)$ were diagnosed with GDM. ${ }^{8}$ In Khurana $\mathrm{M}$ et al study $5.3 \%$ of study population had GDM tested by OGTT. ${ }^{9}$ American diabetic association (ADA) noticed that $7 \%$ of all pregnancies are complicated by GDM. In our study population also GDM prevalance is found to be $7.4 \%$.

It is expected that prevalence of GDM in a population will depend on the age distribution of the population studied. A number of investigators have found that maternal age is highly correlated with risk of GDM. However as age increases prevalence of GDM also increases linearly. In the present study, $76.3 \%$ of patients were less than 25 years and the rest $23.7 \%$ were under the risk category (age $>25$ years). The higher number of $<25$ years age may probably be due to traditions followed in Indian culture like(especially South India) with regard to marriage and conception at an early age. The migrant Indians in other parts of world show very high prevalence of GDM. This can again be due to the fact that they postpone pregnancy to a later age for various reasons like career orientation etc. In a study done by Dixon DRD et al in Rochester, Minnesota, they observed that a majority of the study population falls in the risk age group and thus the expectation of increased prevalence in GDM. ${ }^{10}$

In our study it was found that $54 \%$ of GDM women were multigravidas, $46 \%$ being Primis.

Increased incidence in multigravidas raises the suspicion that at least some percentage of them must be having undiagnosed glucose intolerance in previous pregnancies and spotted out only in the index pregnancy.

Various risk factors are found in association with GDM, prevalence of these risk factors among GDM cases is stressed in many studies. Age $>25$ years is found to be the most prevalent risk factor ranging from 44\%-90\%. In a western study done by Dixon DRD et al in Rochestar, Minnesota, the age risk factor (>25years) contributing to almost $90.4 \% .{ }^{10}$ Studies done by Bhattacharya et al and Jindal et al the corresponding figures were $66 \%$ and $44.4 \%$ respectively. In the study of Ramalingam et al also age $>25$ years was the common risk associated with GDM following by past history of fetal loss. ${ }^{11,12}$ In our study also age appears to be the dominant risk factor $(88.3 \%)$ as is in par with that of Dixon et al. ${ }^{8}$ Despite the earlier tradition and customs of early marriages and teenage pregnancies, still in some parts of India the higher percentage of GDM women with age $>25$ years can be due to change in social trends. Presently in India women are educating themselves gaining employment and building their carrier which inevitably delay the age of marriage and pregnancy The second most common risk factor is found to be obesity as per the study of Dixon DRD et al this risk was seen in $47 \%$ whereas in our study the corresponding figure is $58.1 \%{ }^{8}$ This can be explained due to the present day life styles which includes the food habits and physical inactivity. This contributes to the increased pre-pregnancy weight and consequently with increased GDM prevalence. As 
specified in best practice and research clinical endocrinology and metabolism that obesity among females of reproductive age has increased three fold since 1979, which causes an additional threefold risk of developing GDM. So there is need for pre-conceptional counseling to the women to avoid this risk.

There was an active debate whether GDM was an actual disease at all that warrants treatment. With the observations of two well conducted large multi-centric randomized clinical trials both of which showed maternal and neonatal benefits following treatment. After accepting that GDM is noteworthy in detection there started an ongoing debate till date and it remains a contentious issue, whether it is universal or selective screening to be adopted. Selective screening reduces the number of women screened and decreases the burden on health care system, while increasing the number of cases being missed to be diagnosed. In a population based study as per the ACOG screening criteria of 6214 universally screened women, Coustan et al reported that $35 \%$ of patients with GDM would have been missed while saving only $\$ 32$ per case. ${ }^{12}$ In our study with the concept of universal screening abnormal OGCT is seen in $46.6 \%$ of group A (without risk factors) and $53 \%$ of group B (with risk factors). Women with positive OGCT when subjected to OGTT $40.2 \%$ and $48.9 \%$ were found to be having abnormal OGTT in Group A and B respectively. This obviously shows that with selective screening alone $40.2 \%$ of cases of GDM would have been missed for diagnosis. This is the strength of our study clearly demonstrating universal screening is superior over selective screening.

In well managed GDM, maternal complications are expected to be less. Pregnancy induced hypertension (PIH) is expected to be common in these pregnancies because protein glycosylation and glucose auto oxidation can lead to the formation of free radicals, possibly inducing lipid peroxidation. An important factor responsible for the development of oxidative stress and reactive oxygen species is hyperglycemia. In study of Thomas B et al $14.41 \%$ of women were complicated with $\mathrm{PIH}, 3.60 \%$ of the women were complicated with oligohydraminos and $2.70 \%$ were complicated with polyhydraminos. ${ }^{13}$ In our study PIH is observed mostly in elderly GDM cases. One among them developed HELLP syndrome which could be attributed to her non complaint attitude and we had to induce her delivery prematurely at 32 weeks and the baby with birth weight of $1.5 \mathrm{~kg}$ survived. Of course hydramnios is expected in these cases due to associated fetal polyuria. In $12.1 \%$ of our cases there was hydramnios but none of them had any associated complications like abruption, preterm labor etc. Since our study population is recruited at an early gestational period of less than 20 weeks a well delivered quality care must have contributed to the better outcome of pregnancies with minimum number of complications.

Obstetric management has undergone tremendous changes in tackling GDM as well as diabetic pregnancies.
The incidence of cesarean section is definitely higher than in non-diabetic population but possibly this is a consequence of the diagnosis and not the condition per se (clinician's distress). In study of Thomas B et al the rate of caesarean delivery was high with $93 \% .{ }^{13}$ Study done by Alberico et al shows caesarean section rate around $50 \%$ which is nearer to ours $(59 \%)$. The reason for our high rate may be-this study being done in a tertiary care hospital with majority of cases being high risk pregnancies with associated co-morbidities being referred from outside hospitals and nursing homes. A minor percentage contributed by failed inductions and fetal distress. In all our previous caesarean section cases with other co-morbidities like GDM with associated macrosomia we decide for elective cesarean section. Thus our cesarean section rate is significantly expected to be high. $25.5 \%$ of our vaginal deliveries were instrumental mostly by ventuose. The major indication we observed was uterine inertia (not responding to oxytocin) and we do believe that resistant uterine inertia as a sequel to GDM.

Neonates born to mothers with GDM are undoubtedly at increased risk for some or the other complications if left unnoticed .There is one unexplained still birth in our study $(1.3 \%)$ which could not be directly attributed to GDM. This case is a primi gravida with no risk factors. She had early booking; she was well managed antenatally with diet alone up to 26 weeks later kept on insulin and was well under control with no evidence of macrosomia and no other co-morbidities. But during her $37^{\text {th }}$ week she felt sudden loss of fetal movements and came to hospital and to our surprise IUD was diagnosed. Following her vaginal delivery fetal autopsy also did not reveal any positive findings. Having experienced that calamity we now have second thoughts about taking GDM pregnancies to term even if they are well under control.

Congenital anomalies in various studies done by Jindal et al and Balituvaicience et al were $2.6 \%$ and $8.6 \%$ respectively in the GDM complicated pregnancies. In study of Nigam A et al congenital malformations identified in $10 \%$ of diabetic pregnancies which were largely anatomical defects (cleft lip, cleft palate, foot drop, hip dislocation), or involved the cardiovascular (pericardial effusion) or nervous system (anencephaly, meningocele). ${ }^{14,15}$ Our results are quite different from them. Only one baby $(1.3 \%)$ was found to have congenital heart disease (VSD). This case was a multigravida (G2P0D1) with strong family history of Diabetes but no positive past history any time. It was a late booking ( 26 weeks) with very high blood sugars and increased $\mathrm{HbA} 1 \mathrm{C}$ levels. We presume that she must have been Diabetic before also with very high levels during the period of organogenesis itself. Since it was a late booking with irregular visits baby could be diagnosed to have the heart defect only after delivery. This obviously indicates the need for early booking to avoid such associated calamities. Pre-pregnancy counseling is also equally important in women with risk factors. Neonatal 
Hypoglycemia was observed in our study $(2.7 \%)$ is small when compared to the study by Balituvaicience et al showing $10.6 \% .^{15}$ Even this small percentage also that occurred in our study is probably due to hypoglycemia caused by insufficient feeds due to maternal ignorance. Macrosomia was seen in $5.4 \%$ of our cases when compared to Balituvaicience et al showing $28 \% .^{15}$ In our study this is mostly observed in women with late booking and with non-complaint attitudes. Apart from universal screening and diagnosis, adequate regular treatment is mandatory for a successful pregnancy outcome. Over all neonatal out-come was satisfactory in our cases because apart from our antenatal care we made available the neonatologist during delivery for immediate care and resuscitation of the baby and babies were also observed in NICU for a reasonable period to avoid immediate complications like neonatal hypoglycemia etc.

\section{CONCLUSION}

Universl screening for GDM is definitely superior over selective screening so as not to miss even a single case. As Indians are found to be ethnically more prone it is mandatory to screen all pregnant women adopting the policy of universal screening to reduce short term as well as long term maternal and perinatal morbidity and mortality.

\section{Funding: No funding sources}

Conflict of interest: None declared

Ethical approval: The study was approved by the Institutional Ethics Committee

\section{REFERENCES}

1. Harrison's Principles of Internal Medicine. $16^{\text {th }}$ ed. McGraw-Hill; 2005:2152-2153.

2. Park's Preventive and Social Medicine. $18^{\text {th }}$ ed. Banarsidas Bhanot; 2005:312-314.

3. First International workshop. Conference on gestational diabetes: summary and recommendations. Diabetes Care. 1980;3:499-501.

4. American diabetes association: summary and recommendations of second International workshop Conference on Gestational Diabetes mellitus. Diabetes. 1985;34(2):123-6.

5. Metzger BE. The organising committee: summary and recommendations of third International workshop. Conference on gestational diabetes mellitus. Diabetes. 1991;40(2):197-201.

6. Metzger BE, Coustan DR. Summary and recommendations of the fourth international workshop conference on gestational diabetes mellitus. Diabetes Care. 1998;21:161-7.

7. Robert G, Moses MD, Cheung NW. Point: Universal screening for GDM. Diabetes Care. 2009;32(7);1349-51.

8. Dahiya K, Sahu J, Dahiya A. Maternal and fetal outcome in gestational diabetes mellitus. A study at tertiary health center in northern India. Open access library journal; 2014:1:e500.

9. Khurana M, Shetty M, Anand M. The clinical study of gestational diabetes mellitus. Journal of Evolution of Medical and Denta Sciences. 2015;4(29):4979-85.

10. Dixon DRD, Winter JTV, Nelson RL, Ogburn PL. Universal versus selective gestational diabetes screening: application of 1997. American Diabetes Association Recommendation Am J Obstet Gynecol. 1997;181:798-802.

11. Ramalingam K, Devisrimurari, Mounica, Bollu, Shaik, Ali F. Pregnancy outcome in gestational diabetes milletus. A prospective observational study. Indian Journal of Obstetrics and Gynecology Research. 2015;2(3):137-48.

12. Coustan DR, Nelson C, Carpenter MW, Carr SR, Rotondo L, Widness JA. Maternal age and screening for gestational diabetes: a population based study. Obstet Gynecol. 1989;73:557-61.

13. Varghese R, Thomas B, Hail MA, Rauf A, Sadi MA, Sualiti AA, et al. The prevalence, risk factors, maternal and fetal outcomes in gestational diabetes mellitus. International Journal of Drug Development And Research. 2012;4(3):356-68.

14. Jindal A, Ahmed F, Bhardwaj B, Chaturvedi B. Prevalence, clinical profile and outcome of gestational diabetes mellitus. J Obst Gyn of India. 2001;30(4):333.

15. Baliutavicience D, Petrenko V, Zalinkevicious R. Selective or universal diagnostic testing for gestational diabetes mellitus. Int J Gynaecol Obstet. 2002;78(3):207-11.

16. Saxena P, Tyagi S, Prakash A, Nigam A, Trivedi SS. Pregnancy outcome of women with gestational diabetes in a tertiary level hospital of North India. J Obstet Gynaecol. 2011;6(2):8-11.

Cite this article as: Hymavathi $\mathrm{K}$, Tadisetti $\mathrm{S}$, Polisetty K, Gottipatti MD. Gestational diabetes mellitus-universal versus selective screening. Int J Reprod Contracept Obstet Gynecol 2016;5: 2155-60. 